\title{
Correction to: Subacute thyroiditis during early pregnancy: a case report and literature review
}

\author{
Chao-Fang Bai ${ }^{1+}$, Guang-Hui Shen ${ }^{2+}$, Ying Yang ${ }^{1 *}{ }^{*}$, Ke Yang ${ }^{3}$, Melvin R. Hayden ${ }^{4}$, Yuan-Yuan Zhou ${ }^{1,5}$ and \\ Xing-Qian Geng ${ }^{1}$
}

\section{Correction to: BMC Pregnancy Childbirth 22, 19} (2022)

\section{https://doi.org/10.1186/s12884-021-04368-2}

Following publication of the original article [1], one of the authors was mistakenly deleted in the proof. The complete author names are listed below:

Chao-Fang Bai ${ }^{1, \dagger}$, Guang-Hui Shen ${ }^{2, \dagger}$, Ying Yang ${ }^{1, "}$, Ke Yang $^{3}$, Melvin R. Hayden ${ }^{4}$, Yuan-Yuan Zhou ${ }^{1,5}$, and XingQian Geng ${ }^{1}$

The original article has been corrected.

\section{Reference}

1. Bai CF, Shen GH, Yang Y, et al. Subacute thyroiditis during early pregnancy: a case report and literature review. BMC Pregnancy Childbirth. 2022;22:19. https://doi.org/10.1186/s12884-021-04368-2.

\begin{abstract}
Author details
'Department of Endocrinology, Affiliated Hospital of Yunnan University, Second People's Hospital of Yunnan Province, Kunming 650000, Yunnan Province, China. ${ }^{2}$ Institute of Pediatrics of Children's Hospital of Fudan University, Shanghai 201102, China. ${ }^{3}$ Department of Vascular and Cardiology, Ruijin Hospital, Shanghai Jiaotong University of Medicine, Shanghai 201102, China. ${ }^{4}$ Departments of Internal Medicine, Endocrinology Diabetes and Metabolism, Diabetes and Cardiovascular Disease Center, University of Missouri School of Medicine, Columbia, MO, USA. ${ }^{5}$ Department of Endocrinology, The Sixth Affiliated Hospital of Kunming Medical University, Yuxi 650031, Yunnan Province, China.
\end{abstract}

Published online: 31 January 2022

The original article can be found online at https://doi.org/10.1186/s12884021-04368-2.

\footnotetext{
*Correspondence: yangying2072@126.com

${ }^{\dagger}$ Chao-Fang Bai and Guang-Hui Shen contributed equally to this work.

${ }^{1}$ Department of Endocrinology, Affiliated Hospital of Yunnan University, Second People's Hospital of Yunnan Province, Kunming 650000, Yunnan Province, China

Full list of author information is available at the end of the article
}

(c) The Author(s) 2022. Open Access This article is licensed under a Creative Commons Attribution 4.0 International License, which permits use, sharing, adaptation, distribution and reproduction in any medium or format, as long as you give appropriate credit to the original author(s) and the source, provide a link to the Creative Commons licence, and indicate if changes were made. The images or other third party material in this article are included in the article's Creative Commons licence, unless indicated otherwise in a credit line to the material. If material is not included in the article's Creative Commons licence and your intended use is not permitted by statutory regulation or exceeds the permitted use, you will need to obtain permission directly from the copyright holder. To view a copy of this licence, visit http://creativecommons.org/licenses/by/4.0/. The Creative Commons Public Domain Dedication waiver (http://creativeco mmons.org/publicdomain/zero/1.0/) applies to the data made available in this article, unless otherwise stated in a credit line to the data. 